Check for updates

Cite this: RSC Adv., 2018, 8, 27602

\title{
Long-term leaching behaviours of cement composites prepared by hazardous wastes $\uparrow$
}

\begin{abstract}
Zhenzhou Yang, ${ }^{a}$ Ji Ru, ${ }^{d}$ Lili Liu, $^{a}$ Xidong Wang ${ }^{a}$ and Zuotai Zhang (D) *bc
In order to evaluate the long-term environmental impact of Eco-Ordinary Portland Cement (EOPC) prepared by municipal solid wastes (MSS) and hazardous wastes (HW), consecutive leaching tests with a time span of 180 days were conducted on the EOPC composites in the compact and ground forms under deionized and saline water conditions. The results show that the heavy metals investigated can be classified into three groups according to their leaching behaviours. The concentrations of $\mathrm{V}, \mathrm{Pb}, \mathrm{Ni}, \mathrm{Ba}$, $\mathrm{Cd}$ and $\mathrm{Zn}$ in the leachate increase with the leaching time, which can be classified into the first group. $\mathrm{Cu}$ and $\mathrm{Sn}$ are in the second group, and their concentrations increase initially, and decline afterward. $\mathrm{Cr}$ and As are in the third group, and their concentrations decline firstly, followed by a clear increase. Besides, a kinetic study was also conducted in the present study, revealing that the leaching behaviours of heavy metals follow a second-order model. Furthermore, our results suggest that the EOPC is resistant to the saline water, but the application of such materials in marine conditions should be paid attention to due to the pollution of arsenic.
\end{abstract}

Received 30th March 2018 Accepted 26th July 2018

DOI: $10.1039 / \mathrm{c} 8 \mathrm{ra02773k}$

rsc.li/rsc-advances methods. Thus, an appropriate approach for the innocuous disposal of these two wastes is urgently needed.

The integrated utilization of wastes in cement kiln has multiple advantages. Firstly, the high temperature in cement kiln can completely destroy the hazardous organic substances and benefit the environment. Secondly, the wastes can be alternative fuel and raw materials, which can save energy and resources at the same time. Finally, the co-process of wastes in cement kiln can also receive additional subsidy from the government. However, it should be noted that the application of materials involving wastes might threaten the environment and human health. ${ }^{\mathbf{1 0 , 1 1}}$ Thus, the environmental impacts caused by the release of pollutants, especially for the heavy metals are strongly needed to be evaluated during their usage period. Nowadays, many studies have conducted the researches on the leaching behaviors of cementitious materials added with wastes. However, the leaching time in those studies is always in a short period ${ }^{12-14}$ and little studies ever stressed on the longterm environmental impact during the application of those materials. It is known that the short-term leaching can over- or under-estimate the potential leaching of contaminants, which might provide the misled information for the decision makers. ${ }^{15}$ Thus, the long-term leaching test is extremely needed to be conducted in this study. To date, multiple leaching protocols have been proposed to evaluate the leaching characteristics of the building and waste materials. For example, Dutch leaching tests 7345 based on the diffusion was established, ${ }^{\mathbf{1 4}}$ which uses the replenished leaching solvent to evaluate the dissolution of inorganic components in the waste materials during a specific period ( $6 \mathrm{~h}$ to 64 days). Later, the Beijing, Beijing, 100083, P. R. China

$\dagger$ Electronic supplementary information (ESI) available. See DOI: $10.1039 / \mathrm{c} 8 \mathrm{ra02773k}$

${ }^{a}$ Beijing Key Laboratory for Solid Waste Utilization and Management, Department of Energy and Resource Engineering, College of Engineering, Peking University, Beijing Technology, Shenzhen, 518055, P. R. China.E-mail: zhangzt@sustc.edu.cn

${ }^{c}$ The Key Laboratory of Municipal Solid Waste Recycling Technology and Management of Shenzhen City, Shenzhen, 518055, P. R. China

${ }^{i}$ School of Civil and Resource Engineering University of Science and Technology 
NEN 7375 protocol was also proposed to estimate the dissolution of inorganic components from the intact stony building and waste materials in the deionized water condition. Besides, another leaching test, such as CEN/TS 16637-2 test and EPA 1315 were proposed to estimate the hazardous substances from the intact or granular materials. It should be noted that leaching process of those protocols are in the replenished leaching solvent or in a short period. To evaluate the long-term leaching behaviors of cement composites containing wastes in the intact and granular forms in stagnant environmental waters, the modified NEN 7375 protocol was applied in this study, as described in the previous literature..$^{\mathbf{1 0 1 1}, 16,17}$ The ground composites simulated the mortar decomposed over time upon usage and the crush of the cement product before their reutilization. In addition, the investigation on the ground composites in different particle sizes could also help to study the law of dynamics during the heavy metal leaching process.

In the present study, long-term leaching behaviors of cement composites prepared by MSS and HW are investigated. For this purpose, the leaching test based on modified NEN 7375 lasting 180 days was conducted. The cement composites in the compact and ground forms were leached in the deionized water and saline water, simulating the surface water and marine conditions, respectively. Our study is expected to provide useful insights to understand the releasing mechanism of heavy metals from the cement composites prepared by HW and MSS, which can stress the environmental issues on the application of such cement composites containing waste materials and highlight the importance of the public health protection measure.

\section{Materials and methods}

\subsection{Materials}

The Eco-Ordinary Portland Cement (EOPC) obtained from the Beijing Cement Plant was used in the present study, which is classified in P.O. 42.5 according to standard GB175-2007. The cement plant chooses the MSS and HW to substitute part of raw materials to produce cement clinker. The MSS with the moisture content of $80 \%$ was obtained from a sewage treatment plant in Beijing, China. The HW is the mixtures, including waste mineral, paint sludge, printing ink, electroplating sludge, and etc., which have been described in our previous study. ${ }^{18}$

\subsection{Materials characterization}

The chemical compositions of EOPC were determined by X-ray fluorescence spectrometry (XRF, S4-Explore, Bruker), while the mineral phases were identified by X-ray diffractometer (XRD, D/ Max 2500, Rigaku). Inductively Coupled Plasma Mass Spectrometry (ICP-MS, XSERIES 2, Thermo Scientific) was used for the heavy metals detection in the EOPC and the quality control is described in ESI. $\dagger$ Before the ICP-MS measurement, a microwave digestion was applied for the digestion of EOPC. Briefly, about $0.5 \mathrm{~g}$ of EOPC was digested in an acid mixture of $\mathrm{HNO}_{3}$ $(69 \%, 5 \mathrm{~mL})$ and $\mathrm{HF}(40 \%, 1 \mathrm{~mL})$, and the residual liquid was heated at $120{ }^{\circ} \mathrm{C}$ for the removal of $\mathrm{HF}$. The detailed digested procedures have already been described in the literature. ${ }^{19}$
Besides, the mercury intrusion porosimetry (MIP, Autopore IV 9510, Micromeritics) was used to measure the characterization of porosity of cement composites.

\subsection{Preparation of cement composites}

The cement composites in this study were prepared by EOPC, aggregate and deionized water. The aggregate used in this study was the standard sand from the Xiamen ISO Standard Sand Co., LTD. The deionized water was produced from a Barnstead NANOpure ultrapure water system (Barnstead, Thermo Scientific, USA) with the resistivity of $18 \pm 1 \mathrm{M} \Omega \mathrm{cm}^{-1}$. The cement/ aggregate/water weighted ratio was $1: 3: 0.5$ and the size of the cement composite was $40 \mathrm{~mm} \times 40 \mathrm{~mm} \times 160 \mathrm{~mm}$. The mechanical property test was subsequently conducted on the cement composites according to the GB/T 17671-1999. It should be noted that two kinds of cement composites (compact and ground) were prepared in this study. The ground composites were prepared by the crush of compact ones and can be classified into coarse particles (particle size $\sim 1 \mathrm{~cm}$ ), and fine particle (particle size $\sim 1 \mathrm{~mm}$ ). The compact composites simulate the intact mortars, while the ground composites simulate the different levels of decomposition of the intact mortars during their usage period.

\subsection{Long-term leaching test}

To evaluate the long-term leaching behaviors of the cement composites containing wastes, the modified NEN 7375 protocol was applied in this study. Herein, two leaching solvents, deionized water and saline water were applied. Deionized water was used to simulate the surface water. Saline water with $3.8 \mathrm{wt} \% \mathrm{NaCl}$ was prepared according to the standard GB865088 , which was used to simulate the marine condition. The leaching test was conducted in a polyethylene vessel with the liquid-solid ratio of $5: 1$. During the leaching process, every $10 \mathrm{~mL}$ samples was taken after 3, 7, 14, 30, 60, 90, 120, 150 and 180 days. Then, the $\mathrm{pH}$ values and the conductivities of samples were measured by the pH meter (MP 220, Mettler-Toledo) and conductivity meter (FE 30, Mettler-Toledo). Besides, the heavy metals concentrations in the samples were also determined by the ICP-MS. After the whole leaching process, the cement composites were taken out for the mechanical strength tests. All the tests were run in triplicate to check the reproducibility.

\section{Results and discussion}

\subsection{Characterization of EOPC}

Table 1 shows the elemental compositions of EOPC. It can be seen that $\mathrm{CaO}, \mathrm{SiO}_{2}$ and $\mathrm{Al}_{2} \mathrm{O}_{3}$ are the main components in EOPC. Besides, EOPC also contains multiple heavy metals, and $\mathrm{Mn}, \mathrm{Zn}$ and $\mathrm{Ba}$ show the higher concentration compared to other heavy metals. XRD patterns (Fig. 1) shows that tricalcium silicate $\left(\mathrm{C}_{3} \mathrm{~S}\right)$, dicalcium silicate $\left(\mathrm{C}_{2} \mathrm{~S}\right)$, tricalcium aluminate $\left(\mathrm{C}_{3} \mathrm{~A}\right)$ and tetra-calcium aluminoferrite $\left(\mathrm{C}_{4} \mathrm{AF}\right)$ are the predominant mineral phases in the EOPC sample, which is similar with the commercial cement. ${ }^{20}$ 


\subsection{Long-term leaching behaviors of the EOPC composite}

To evaluate the long-term leaching behaviors of the cement composites prepared by EOPC, the modified NEN 7375 test was applied on the EOPC composites in the compact and ground forms. The $\mathrm{pH}$ and the conductivity values of the leachate are shown in Table S1.† It can be seen that, the $\mathrm{pH}$ value of the leachate is notably high, in the range of 11 and 13. This can be attributed to the presence of soluble $\mathrm{Ca}(\mathrm{OH})_{2}$ and $\mathrm{CaCO}_{3}$ in the cement composites, which is also in accordance with the previous study. ${ }^{21}$ Besides, the $\mathrm{pH}$ values of leachate from ground composites are obviously higher than those from the compact ones, which can be due to the higher specific area in the ground composites, resulting in the elevated leachability of alkaline species. Conductivity can indicate the ionic strength of the leachate. The results show that, the ionic strength of the leachate in the saline water is much higher than that in the deionized water. Besides, the ionic strength of leachate from ground composites is also higher than that from the compact ones. The higher ionic strength in the saline water can be attributed to the higher concentrations of ions, such as $\mathrm{Na}^{+}$and $\mathrm{Cl}^{-}$in the leaching solvent. ${ }^{21}$ Besides, the higher specific area in the ground composites can promote the leaching of ions $\left(\mathrm{Ca}^{2+}\right.$, $\mathrm{K}^{+}, \mathrm{Na}^{+}, \mathrm{OH}^{-}, \mathrm{SO}_{4}{ }^{2-}$, and etc.), which can elevate the value of ionic strength of the leachate. It also can be seen that the conductivity of the leachate increases rapidly at first, but declines slightly afterward. This can be due that, firstly, the ions

Table 1 Main chemical composition of EOPC (wt\% by weight) ${ }^{a}$

$\begin{array}{llllllllllll}\text { Sample } & \mathrm{CaO} & \mathrm{SO}_{3} & \mathrm{SiO}_{2} & \mathrm{MgO} & \mathrm{Al}_{2} \mathrm{O}_{3} & \mathrm{Na}_{2} \mathrm{O} & \mathrm{TiO}_{2} & \mathrm{~K}_{2} \mathrm{O} & \mathrm{P}_{2} \mathrm{O}_{5} & \text { LOI }\end{array}$

$\begin{array}{lllllllllll}\text { EOPC } & 53.8 & 2.8 & 22.6 & 4.1 & 8.0 & 0.8 & 0.5 & 0.8 & 0.2 & 3.2\end{array}$

$\begin{array}{lllllllllllll}\text { Sample } & \mathrm{As} & \mathrm{Ba} & \mathrm{Cd} & \mathrm{Co} & \mathrm{Cr} & \mathrm{Cu} & \mathrm{Ni} & \mathrm{Pb} & \mathrm{Zn} & \mathrm{Mn} & \mathrm{V} & \mathrm{Sn}\end{array}$

$\begin{array}{lllllllllllll}\text { EOPC } & 94 & 157 & 0.6 & 3 & 4.4 & 19 & 9 & 23 & 101 & 673 & 30 & \mathrm{Nd}\end{array}$

${ }^{a} \mathrm{Nd}$ : not detected.

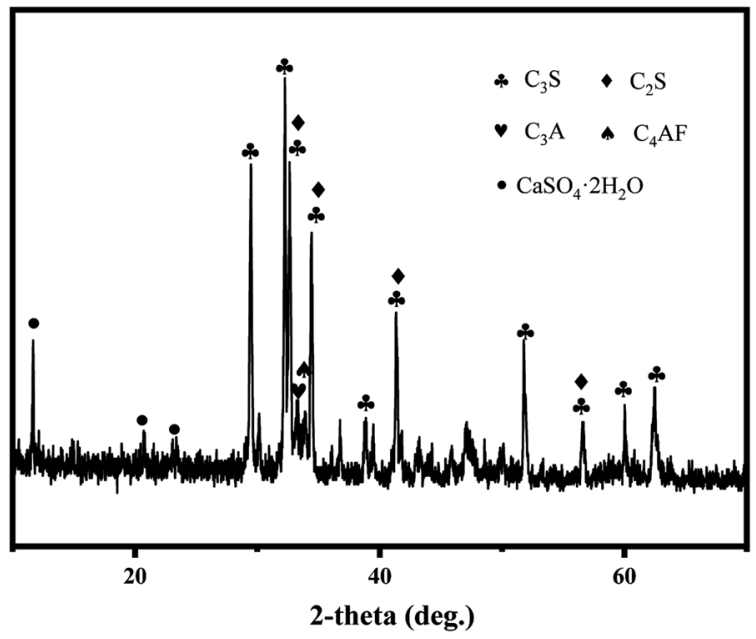

Fig. 1 XRD pattern of EOPC. can be dissolved in leachate rapidly, which can elevate the conductivity of the leachate. ${ }^{22}$ With the hydration going on, $\mathrm{Ca}^{2+}$ and some anions can be adsorbed by the hydrated product such as ettringite (AFt), which can thereby decrease the conductivity of the leachate..$^{23}$ In addition, the $\mathrm{pH}$ value of leachate declines slowly with the leaching time, which can be ascribed to the aqueous carbonation effect, and the similar phenomenon was also observed in the previous study. ${ }^{24}$

The concentrations range of heavy metals in the leachate under different conditions and the maximum values set by the corresponding regulation are shown in Table 2. It can be seen that, most heavy metals show the low leachability and the concentrations of them are much lower than the corresponding regulation. This can be attributed to the high $\mathrm{pH}$ value in the leachate (Table S1†). Under the high alkaline conditions, most heavy metals can be precipitated. The occurrences of heavy metals can be calculated according to the geochemical model, which has been shown in the previous study. ${ }^{25}$ For example, Ni can precipitate as $\mathrm{Ni}(\mathrm{OH})_{2} \cdot{ }^{25}$ Besides, the formation of $\mathrm{Ni}-\mathrm{Al}$ layered double hydroxide (LDH) phases under the alkaline condition can also stabilize $\mathrm{Ni}$ in the leachate. ${ }^{26} \mathrm{Zn}$ can be stabilized by the precipitation of $\mathrm{CaZn}_{2}(\mathrm{OH})_{5} \cdot 2 \mathrm{H}_{2} \mathrm{O}$ (calcium zincate) at the alkaline condition, ${ }^{27}$ and the similar reaction was also observed for $\mathrm{Cu}$ and $\mathrm{Pb}^{.5}$ Besides, the heavy metals can also be incorporated in hydrate phases of $\mathrm{C}-\mathrm{S}-\mathrm{H}$, AFt and monosulphate (AFm) in the cement composites. It is known that some heavy metals in the forms of oxyanionic species, such as $\mathrm{CrO}_{4}{ }^{2-}$ and $\mathrm{MoO}_{4}{ }^{2-}$ can replace the $\mathrm{SO}_{4}{ }^{2-}$ in AFt and $\mathrm{AFm}$, then can be incorporated in the mineral phases. ${ }^{23}$ Moreover, some heavy metals such as $\mathrm{Cd}, \mathrm{Pb}, \mathrm{Zn}$, and etc. can also substitute $\mathrm{Ca}^{2+}$ in $\mathrm{C}-\mathrm{S}-\mathrm{H}, \mathrm{AFm}$ and AFt by ion exchange. ${ }^{25}$ Although the concentrations of most heavy metals are below the limitation of regulation, the concentration of As exceeds the corresponding regulation in the saline water. This indicates that the pollution of As should be prevented when this kind of material is implemented in the marine condition. As can be seen that, the concentrations of most heavy metals in the leachate from ground composites are higher than those from compact composites. These elements also show higher leachability in the fine particle compared to those in the coarse particle, which can be attributed to the higher specific area in ground composite and fine particles. It is well known that the $\mathrm{pH}$ value can significantly affect the leaching of heavy metals and the minimum leaching of heavy metals usually occurred in the neutral condition. ${ }^{28}$ Thus, in order to control the leaching of heavy metals, some measures must be taken to decrease the $\mathrm{pH}$ value of the leachate.

According to the different leaching behaviors, we can classify the heavy metals into three groups. In the first group, the concentrations of $\mathrm{V}, \mathrm{Pb}, \mathrm{Ni}, \mathrm{Cd}, \mathrm{Ba}$ and $\mathrm{Zn}$ in the leachate increase parabolically with the leaching time, indicating the leaching of those heavy metals are controlled by the dissolution and diffusion. However, the leaching behaviors of some heavy metals in this group show some differences. For example, the concentration of $\mathrm{V}$ in the leachate from the compact composites is much higher than that from the ground composites (Fig. 2). This can be due that higher content of $\mathrm{Ca}^{2+}$ can be leached out 
Table 2 The concentration $\left(\mu \mathrm{g} \mathrm{L}^{-1}\right.$ ) ranges of the elements in the deionized and saline leachates from compact, coarse particle and fine particle composites prepared with EOPC during the course of the experiment (180 days $)^{a}$

\begin{tabular}{|c|c|c|c|c|c|c|c|}
\hline $\mathrm{Cr}$ & $0.9-3.5$ & $0.7-1.4$ & $1.1-2.2$ & $41.3-49.3$ & $34.8-55.8$ & $36.3-44.5$ & 300 \\
\hline V & $0.3-1.6$ & $2.7-11.6$ & $3.3-11.5$ & $0.3-2.1$ & $3.3-12.8$ & $5.2-11.4$ & - \\
\hline $\mathrm{Ni}$ & $3.7-17.3$ & $21.1-103.3$ & $30.4-142.3$ & $34.4-61.4$ & $55.2-93.5$ & $59.5-95.8$ & 300 \\
\hline $\mathrm{Cu}$ & $1.3-4.5$ & $4.7-13.0$ & $3.8-14.1$ & $12.9-24.9$ & $19.5-35.2$ & $20.4-33.3$ & 1000 \\
\hline $\mathrm{Cd}$ & $0.01-0.02$ & $0.01-0.04$ & $0.01-0.04$ & $0.01-0.1$ & $0.1-0.7$ & $0.3-0.8$ & 100 \\
\hline $\mathrm{Pb}$ & $0.01-0.04$ & $0.3-3.0$ & $0.2-3.6$ & $0.2-0.8$ & $0.2-5.2$ & $0.3-5.5$ & 300 \\
\hline Sn & $0.01-0.35$ & $0.01-0.21$ & $0.01-0.13$ & $0.01-0.84$ & $0.01-0.97$ & $0.01-0.79$ & - \\
\hline
\end{tabular}

${ }^{a}$ Dw: deionized water; Sw: saline water; -: not regulated.

in the ground composites because of the higher surface area. The reaction between the $\mathrm{Ca}^{2+}$ and $\mathrm{V}$ can be thereby promoted, forming the insoluble phase of calcium vanadate. ${ }^{29}$ Besides, $\mathrm{V}$ is usually in the presence of $\mathrm{VO}_{4}{ }^{3-}$ in the alkaline condition. ${ }^{25}$ The smaller particle sizes of cement composites can cause the higher $\mathrm{pH}$ value in the leachate (Table $\mathrm{S} 1 \dagger$ ), which can promote the substitution of $\mathrm{VO}_{4}{ }^{3-}$ in $\mathrm{AFt}$ and $\mathrm{AFm}$. Thus, the concentration of $\mathrm{V}$ in the leachate from the ground composites is lower than that from the compact ones. By contrast, the leaching concentration of $\mathrm{Pb}$ from the ground cement composites is obviously higher than that from the compacts ones (Fig. 3). This indicates that the leaching of $\mathrm{Pb}$ is determined by the surface area of the cement composite. Besides, since $\mathrm{Pb}$ is predominantly precipitated at the $\mathrm{pH}$ around 10 , the higher $\mathrm{pH}$ value in the leachate from the ground composites can increase its leachability. ${ }^{30}$ Therefore, in order to prevent the leaching of $\mathrm{Pb}$, the crushed EOPC composites should be avoided, unless included into other compact building materials. In the second group, the leaching of $\mathrm{Cu}$ and $\mathrm{Sn}$ increases firstly, but declines afterwards with the leaching time (taking the $\mathrm{Sn}$ as an example shown in Fig. 4). The declination can be attributed to the presence of hydroxide from some heavy metals such as iron and manganese, which can be played as adsorbents and impede the leaching of $\mathrm{Cu}$ and $\mathrm{Sn}^{25,31} \mathrm{In}$ the third group, the leaching of $\mathrm{Cr}$ and As declines initially, then followed by a clear increase (taking the $\mathrm{Cr}$ as an example shown in Fig. 5). The declination can be attributed to the substitution in ettringite-type phases, which is also in accordance with the previous study. ${ }^{25}$ Later, the concentrations of $\mathrm{Cr}$ and As increase as more $\mathrm{Cr}$ and As can be leached out with the increase of leaching time.

\subsection{Kinetic study}

In order to explore the leaching mechanism of heavy metals during the long-term leaching process, the kinetic study under the different conditions was conducted. For the description of solid-liquid reacted system, multiple kinetic models, such as reaction-controlled and diffusion-controlled models have been proposed. However, the results demonstrate that those kinetic models did not show a good agreement with the experimental data. Thus, another kinetic model must be provided to describe the leaching process in this study. Considering the observation from this study that, most of heavy metals in the cement
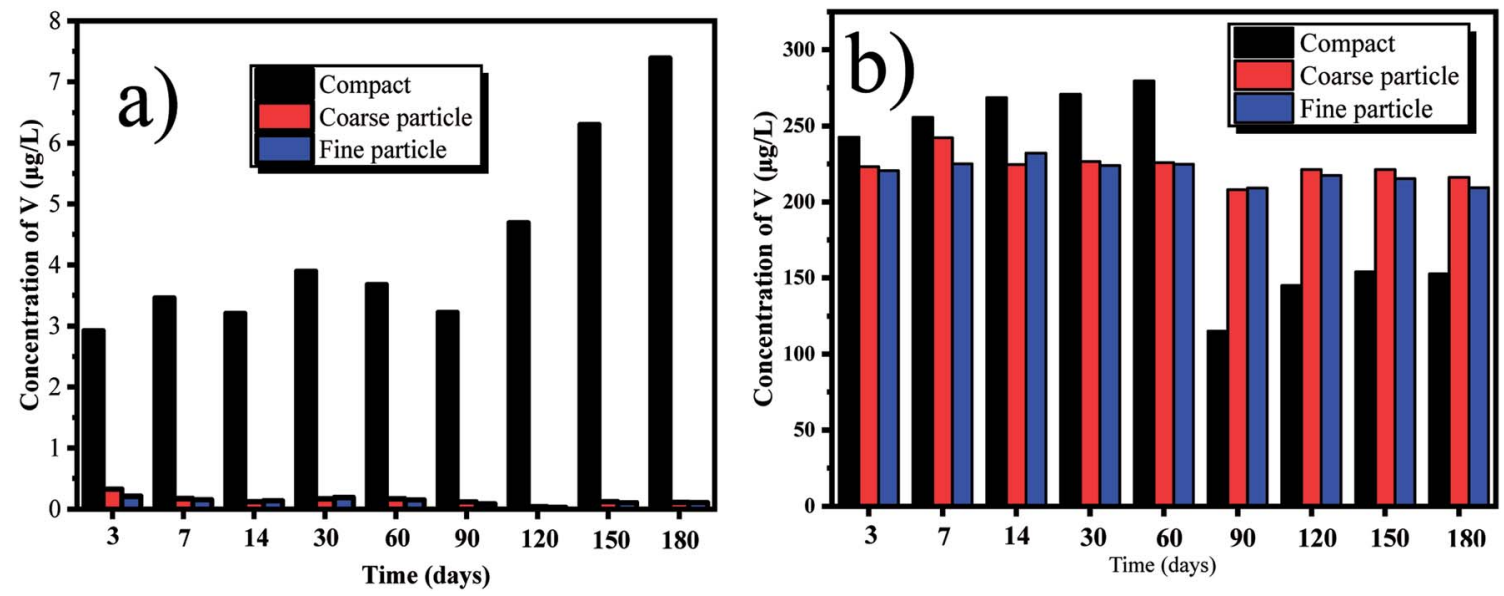

Fig. 2 Leaching of $\bigvee$ with deionized water and saline water over time, from the tested compact, coarse particle and fine particle: (a) deionized water; (b) saline water. 

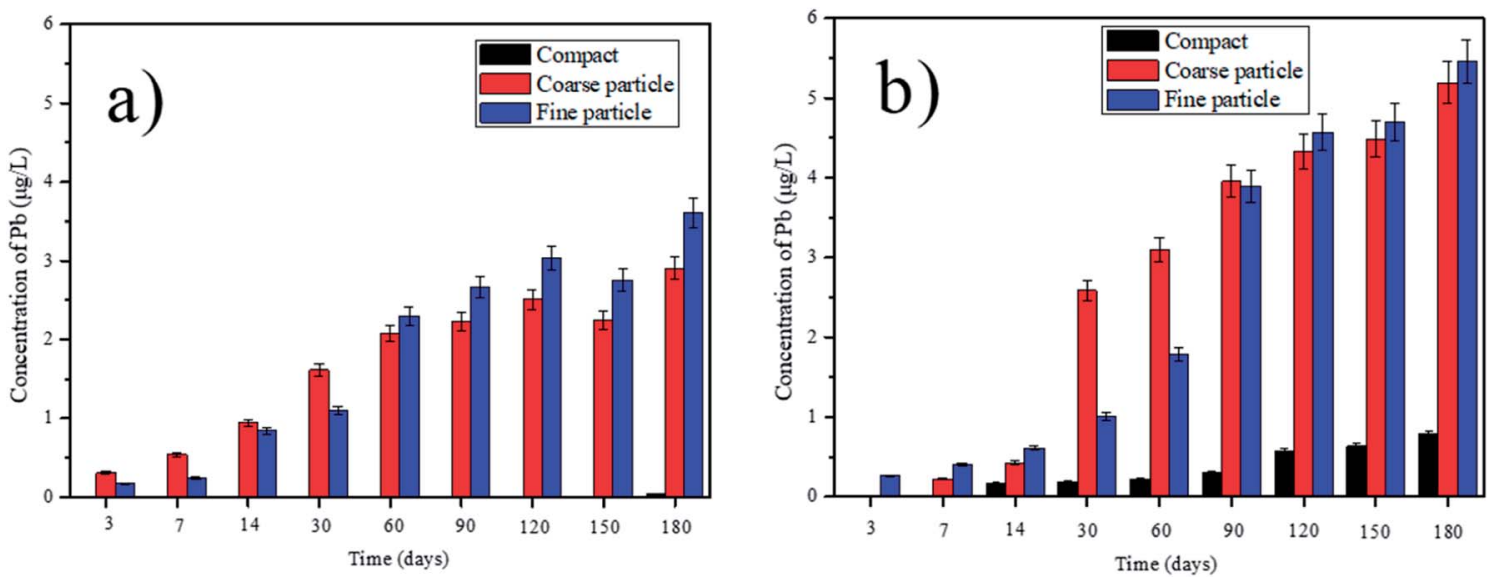

Fig. 3 Leaching of $\mathrm{Pb}$ with deionized water and saline water over time, from the tested compact, coarse particle and fine particle: (a) deionized water; (b) saline water.

composites are released quickly at first, then the leaching process becomes much slower. Finally, the equilibrium state can be reached. This indicates that the kinetic model might follow the second-order law. The general form of the secondorder kinetic model has been described previously by Lee et al., ${ }^{32}$ which is shown in eqn (1),

$$
\frac{t}{C_{t}}=\frac{1}{K C_{\mathrm{s}}^{2}}+\frac{t}{C_{\mathrm{s}}}
$$

where $C_{t}$ is the concentration of heavy metals in the leachate in the time of $t$. $C_{\mathrm{s}}$ is the concentration of heavy metals in the leachate at the equilibrium state, while $K\left(\mathrm{~L} \mathrm{mg}^{-1} \mathrm{~min}^{-1}\right)$ is the rate constant of reaction. The slope $1 / C_{\mathrm{s}}$ and the intercept $1 / K C_{\mathrm{s}}^{2}$ can be calculated by the linear fitting between the $t / C_{t}$ and $t$. Herein, we take the $\mathrm{Pb}$ for an example, and Table 3 shows the fitting results under different conditions. The results show that the coefficients of determination $\left(R^{2}\right)$ of the fitting values are all above 0.95 , and the similar results are also found in other heavy metals. This indicates that the diffusion is the controlling leaching mechanism during the heavy metals leaching process. As a kind of porous materials, cement composites contain a large number of intercommunicating pores and closed pores (Fig. S1 $\dagger$ ). Thus, the leaching process can be described as: firstly, the heavy metals adhered on the surface of the cement composites can be leached out rapidly due to the driving force of the fresh water and a reacted layer with fewer heavy metals was subsequently appeared. In this step, the concentrations of heavy metals in the leachate will increase rapidly. In the second step, the heavy metals inside the cement composites can be diffused out through the reacted layer, then enter the liquid phase through the water firm. Due to the higher concentrations of heavy metals in the leachate, the leaching rate is much slower in this step because of the weak drive of mass transfer. Besides, the refractory phases in the cement composites might act as a blocker, hinder the diffusion of heavy metals in the closed pores or in the matrix of cement composites. Further, the hydration of cement composites lasts all the time during the leaching process, which will lead to a denser structure of cement composites, and thus increase the diffusion resistance. As aforementioned, we can propose some methods to control the leaching of heavy metals. For example, in the first step, we
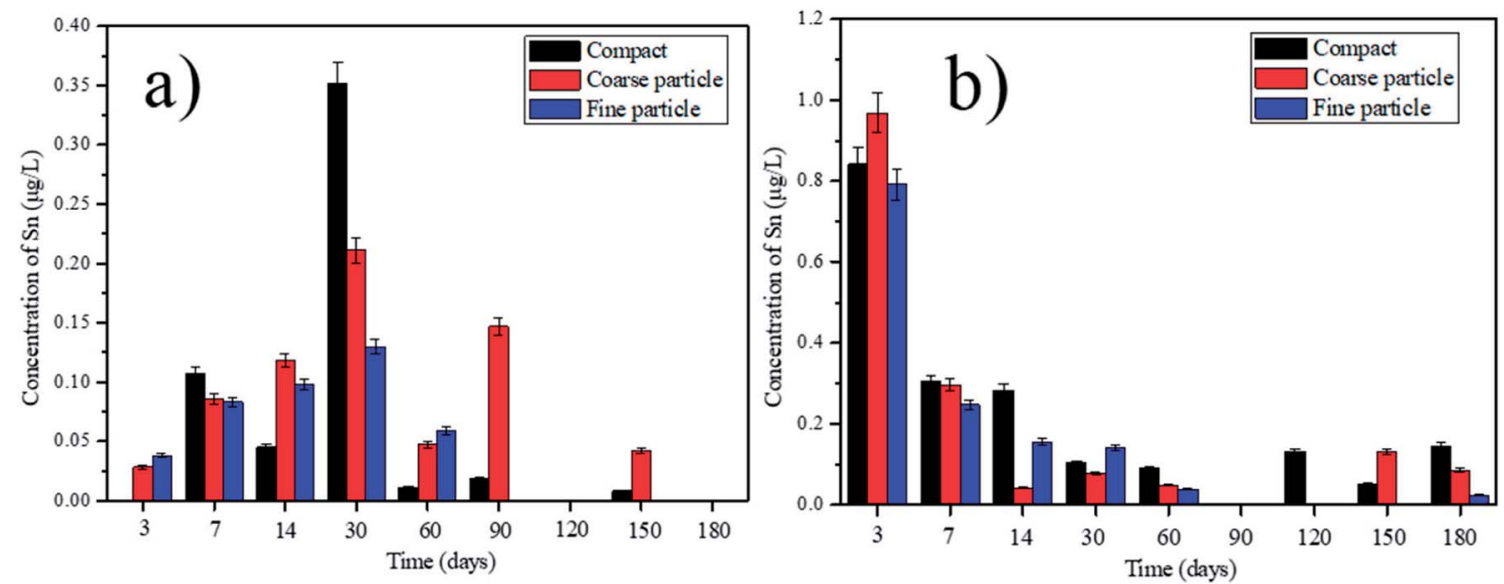

Fig. 4 Leaching of Sn with deionized water and saline water over time, from the tested compact, coarse particle and fine particle: (a) deionized water; (b) saline water. 

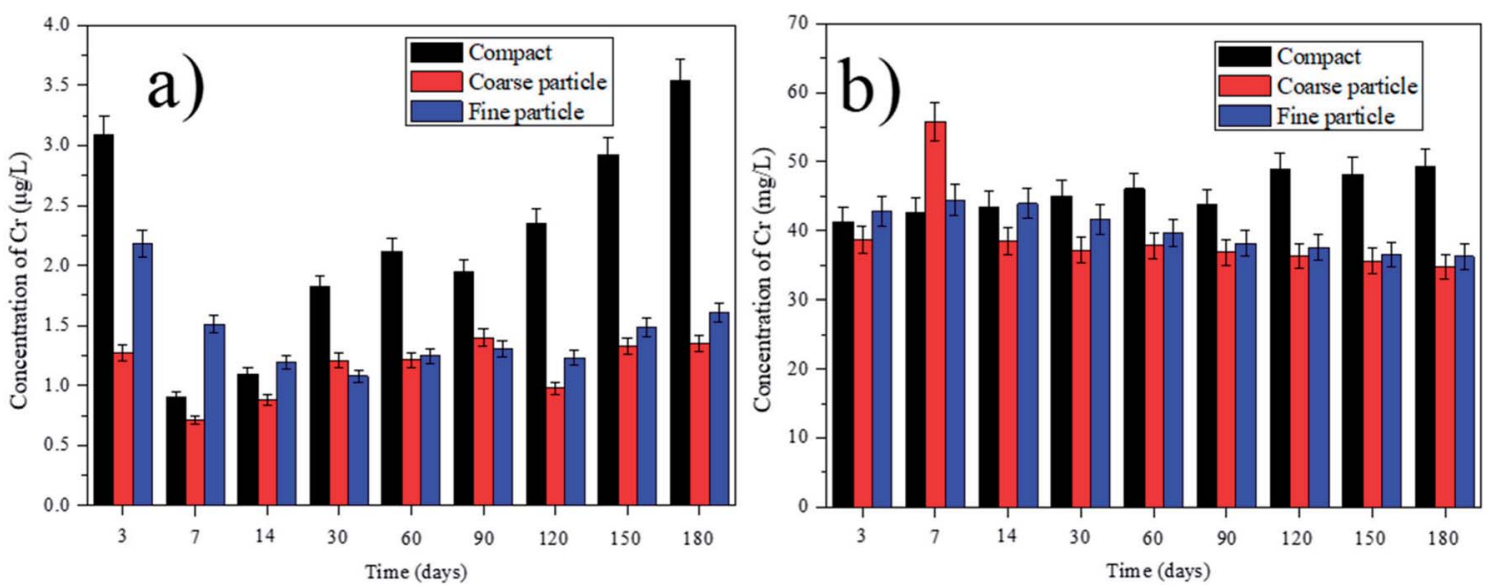

Fig. 5 Leaching of $\mathrm{Cr}$ with deionized water and saline water over time, from the tested compact, coarse particle and fine particle: (a) deionized water; (b) saline water.

Table 3 Determination coefficients $\left(R^{2}\right)$ if various kinetic models for the leaching of $\mathrm{Pb}$

\begin{tabular}{lll}
\hline & State of cement & \\
Leaching condition & $R^{2}$ \\
\hline \multirow{2}{*}{ Deionized water } & Compact & 0.962 \\
& Coarse particle & 0.995 \\
Saline water & Fine particle & 0.996 \\
& Compact & 0.983 \\
& Coarse particle & 0.965 \\
& Fine particle & 0.981
\end{tabular}

can slow down the flow velocity of water because the external diffusion is dominant. Further, the crushed cement composites should be avoided in second step due to the leaching rates of heavy metals are controlled by the internal diffusion in this step.

\subsection{The mechanical strength test}

The mechanical property of compact cement composites before and after the leaching process is shown in Fig. 6. It can be seen that the compressive strength of cement composites before leaching is much lower than that after leaching. The leaching medium can determine the strength of cement composites in two aspects. ${ }^{33}$ Firstly, the leaching medium can provide the hydrated environment for the cement composite, which can promote the formation of a denser structure, resulting in the higher strength of the composites. Secondly, $\mathrm{H}^{+}$in the leaching medium can corrode the structure of cement composite, which can damage its strength. In this study, the corrosion caused by the $\mathrm{H}^{+}$is impeded because the highly alkaline condition (Table S1†) and the ongoing hydrated process can benefit for the strength of the cement composites. As can be seen that, the compressive strength of cement composites prepared by EOPC in saline water is lower than those in deionized water, which might be due to the corrosive effect caused by the chloride. ${ }^{34}$ In addition, the MIP test is also conducted to describe the porosity parameters of the cement composites after the leaching process and the results are displayed in Table $\mathrm{S} 2 \dagger$ and Fig. 7. The results show that the composites leaching in the saline water contain the lowest overall porosity. The most probable reason can be attributed to the formation of Friedel's salt, which can cause the refinement and reduction of the pore volume. ${ }^{35}$ Furthermore, a criterion to identify the resistant/durable ability of materials
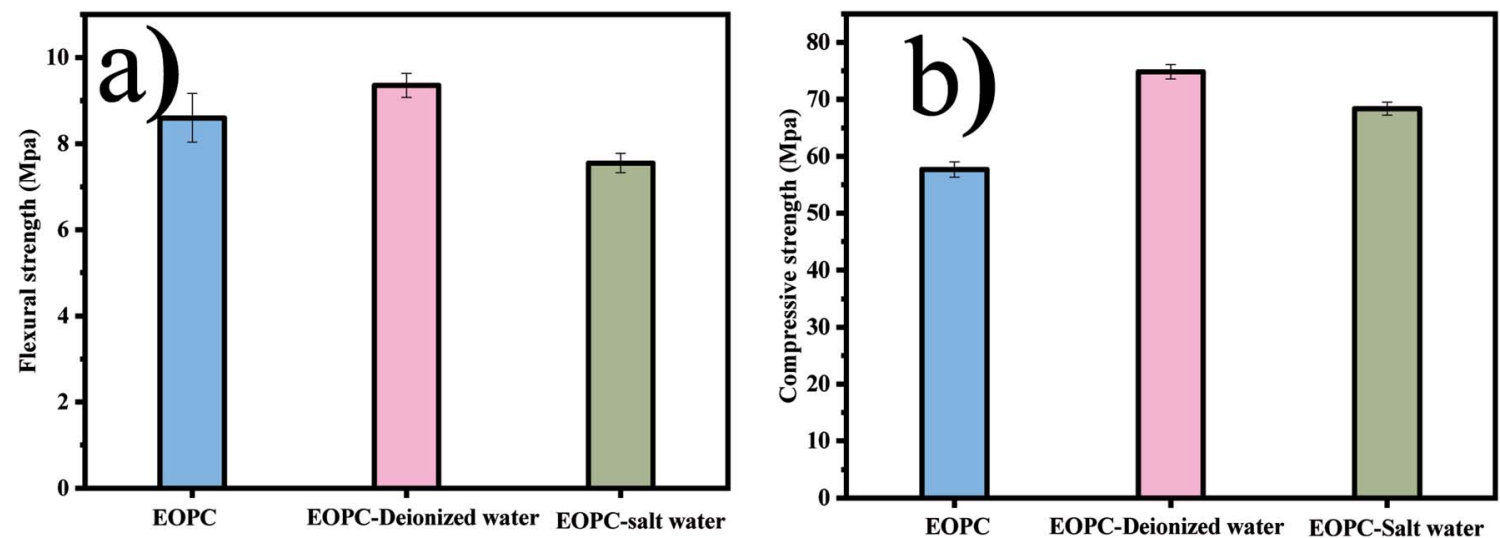

Fig. 6 The mechanical properties of OPEC under different leaching environment: (a) flexural strength (b) compressive strength. 


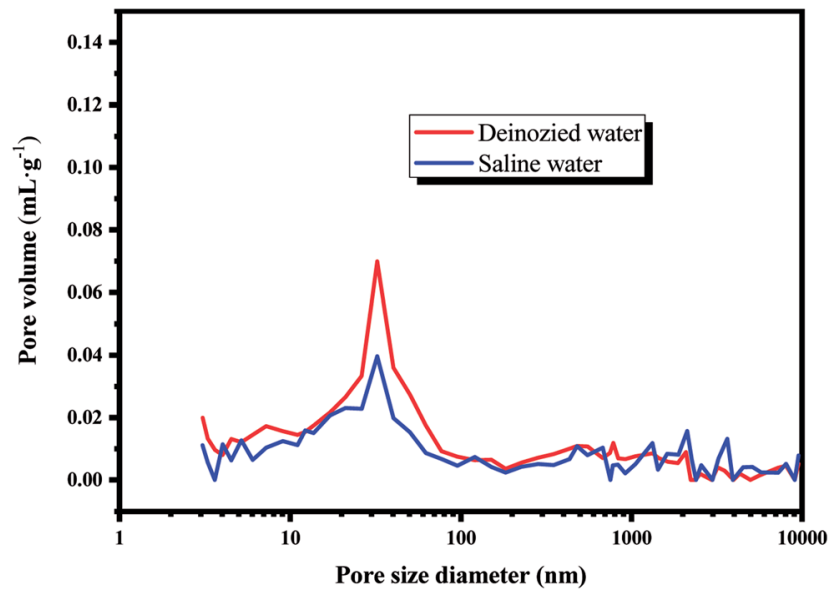

Fig. 7 Pore size distribution curves, determined by MIP, for the investigated compact composites prepared by EOPC, after 180 days of exposure to deionized water and saline water.

in saline water was also proposed in our study as a corrosion index $\left(I_{c}\right)$, which can be calculated by the relative strength of samples in saline water to those stored in water. ${ }^{36}$ The $I_{\mathrm{c}}$ of the cement composites prepared by EOPC is 0.8 , higher than the general value of 0.7 , which is resistant to saline water.

\section{Conclusion}

The long-term leaching behaviors of cement composites prepared by EOPC are investigated in this study. Compact and ground (coarse particle and fine particle) cement composites are prepared and the leaching test based on the modified NEN 7375 procedure is conducted in deionized water and saline water with a time span of 180 days. Our results show that concentrations of most heavy metals are below the limitation of corresponding regulation, except for the As in the saline water condition. Besides, we can classify the heavy metals into three groups. In the first group, the concentrations of $\mathrm{V}, \mathrm{Pb}, \mathrm{Ni}, \mathrm{Cd}, \mathrm{Ba}$ and $\mathrm{Zn}$ in the leachate increase with the leaching time. $\mathrm{Cu}$ and $\mathrm{Sn}$ are classified into the second group; the concentrations of them increase initially, then decline afterward. The concentrations of $\mathrm{Cr}$ and As decline firstly, followed by a clear increase, and they can be classified into the third group. The kinetic study indicates that the leaching of heavy metals follows a second-order model. Furthermore, our results point out that the cement composites prepared by EOPC are irresistible against saline water, but the application of such a material in the marine environment should be careful due to the pollution of As.

\section{Conflicts of interest}

There are no conflicts to declare.

\section{Acknowledgements}

This study was supported by National Science Fund for Distinguished Young Scholars (51522401) and National Natural
Science Foundation of China (51472007, 51772141). This work was also supported financially by Shenzhen Science and Technology Innovation Committee (ZDSYS201602261932201, JCYJ20170412154335393, KQTD2016022619584022). Additional support was provided by the Southern University of Science and Technology (Grant No. G01296001) and Guangdong Provincial Key Laboratory of Soil and Groundwater Pollution Control (Grant No. 2017B030301012).

\section{References}

1 B. Xiao, Q. Dai, X. Yu, P. Yu, S. Zhai, R. Liu, X. Guo, J. Liu and H. Chen, Effects of sludge thermal-alkaline pretreatment on cationic red X-GRL adsorption onto pyrolysis biochar of sewage sludge, J. Hazard. Mater., 2017, 343, 347-355.

2 H. S. Shi and L. L. Kan, Characteristics of municipal solid wastes incineration (MSWI) fly ash-cement matrices and effect of mineral admixtures on composite system, Constr. Build. Mater., 2009, 23, 2160-2166.

3 M. B. Folgueras, M. Alonso and R. M. Díaz, Influence of sewage sludge treatment on pyrolysis and combustion of dry sludge, Energy, 2013, 55, 426-435.

4 T. Murakami, Y. Suzuki, H. Nagasawa, T. Yamamoto, T. Koseki, H. Hirose and S. Okamoto, Combustion characteristics of sewage sludge in an incineration plant for energy recovery, Fuel Process. Technol., 2009, 90, 778-783.

5 H. B. Zhou, C. Ma, D. Gao, T. B. Chen, G. D. Zheng, J. Chen and T. H. Pan, Application of a recyclable plastic bulking agent for sewage sludge composting, Bioresour. Technol., 2014, 152, 329.

6 J. Jin, M. Wang, Y. Cao, S. Wu, P. Liang, Y. Li, J. Zhang, J. Zhang, M. H. Wong and S. Shan, Cumulative effects of bamboo sawdust addition on pyrolysis of sewage sludge: Biochar properties and environmental risk from metals, Bioresour. Technol., 2017, 228.

7 I. Petersen and J. Werther, Experimental investigation and modeling of gasification of sewage sludge in the circulating fluidized bed, Chem. Eng. Process., 2005, 44, 717-736.

8 M. Inguanzo, A. Domínguez, J. A. Menéndez, C. G. Blanco and J. J. Pis, On the pyrolysis of sewage sludge: the influence of pyrolysis conditions on solid, liquid and gas fractions, J. Anal. Appl. Pyrolysis, 2002, 63, 209-222.

9 P. Sosnowski, A. Wieczorek and S. Ledakowicz, Anaerobic codigestion of sewage sludge and organic fraction of municipal solid wastes, Adv. Environ. Res., 2003, 7, 609-616.

10 A. Drinčić, I. Nikolić, T. Zuliani, R. Milačič and J. Ščančar, Long-term environmental impacts of building composites containing waste materials: Evaluation of the leaching protocols, Waste Manage., 2017, 340-349.

11 T. Šturm, R. Milačič, S. Murko, M. Vahčič, A. Mladenovič, J. S. Šuput and J. Ščančar, The use of EAF dust in cement composites: assessment of environmental impact, $J$. Hazard. Mater., 2009, 166, 277-283.

12 R. Bie, P. Chen, X. Song and X. Ji, Characteristics of municipal solid waste incineration fly ash with cement solidification treatment, J. Energy Inst., 2016, 89, 704-712. 
$13 \mathrm{H}$. Shi and Y. Ling, Cementitious reactivity of municipal solid waste incineration fly ash and immobilization effect by cement, J. Chin. Ceram. Soc., 2003, 31, 1021-2025.

14 I. Hohberg, G. J. D. Groot, A. M. H. V. D. Veen and W. Wassing, Development of a leaching protocol for concrete, Waste Manage., 2000, 20, 177-184.

15 H. Lee, G. Yu, Y. Choi, E. H. Jho and K. Nam, Long-term leaching prediction of constituents in coal bottom ash used as a structural fill material, J. Soils Sediments, 2017, $1-10$.

16 M. Vahcic, R. Milacic, A. Mladenovic, S. Murko, T. Zuliani, M. Zupancic and J. Scancar, Leachability of $\mathrm{Cr}(\mathrm{VI})$ and other metals from asphalt composites with addition of filter dust, Waste Manage., 2008, 2, 2667-2674.

17 R. Milaä, T. Zuliani, T. Oblak, A. Mladenoviä and J. Å. AnäAr, Environmental impacts of asphalt mixes with electric arc furnace steel slag, J. Environ. Qual., 2011, 40, 1153-1161.

18 Z. Yang, Y. Chen, Y. Sun, L. Liu, Z. Zhang and X. Ge, The partitioning behavior of trace element and its distribution in the surrounding soil of a cement plant integrated utilization of hazardous wastes, Environ. Sci. Pollut. Res. Int., 2016, 23, 13943.

19 L. Qi, Y. Zhang, Y. Ma, M. Chen, X. Ge, Y. Ma, J. Zheng, Z. Wang and S. Li, Source identification of trace elements in the atmosphere during the second Asian Youth Games in Nanjing, China: influence of control measures on air quality, Atmos. Pollut. Res., 2016, 7, 547-556.

20 S. Yang, H. Song and R. Xie, XRD Study of Hydration Rate of Cement, J. Instrum. Anal., 1996, 15, 73-76.

21 V. Z. Serjun, A. Mladenovič, B. Mirtič, A. Meden, J. Ščančar and R. Milačič, Recycling of ladle slag in cement composites: Environmental impacts, Waste Manage., 2015, 43, 376-385.

22 A. Princigallo, K. V. Breugel and G. Levita, Influence of the aggregate on the electrical conductivity of Portland cement concretes, Cem. Concr. Res., 2003, 33, 1755-1763.

23 M. Zhang and E. J. Reardon, Removal of B, Cr, Mo, and Se from Wastewater by Incorporation into Hydrocalumite and Ettringite, Environ. Sci. Technol., 2003, 37, 2947.

24 Z. Yang, S. Tian, R. Ji, L. Liu, X. Wang and Z. Zhang, Effect of water-washing on the co-removal of chlorine and heavy metals in air pollution control residue from MSW incineration, Waste Manage., 2017, 68, 221-231.
25 C. J. Engelsen, H. A. V. D. Sloot, G. Wibetoe, H. Justnes, W. Lund and E. Stoltenberg-Hansson, Leaching characterisation and geochemical modelling of minor and trace elements released from recycled concrete aggregates, Cem. Concr. Res., 2010, 40, 1639-1649.

26 A. M. Scheidegger, E. Wieland, A. C. Scheinost, A. Rainer Dähn and P. Spieler, Spectroscopic Evidence for the Formation of Layered Ni-Al Double Hydroxides in Cement, Environ. Sci. Technol., 2000, 34, 4545-4548.

27 F. Ziegler and C. A. Johnson, The solubility of calcium zincate $\left(\mathrm{CaZn}(\mathrm{OH})_{2} \cdot \mathrm{HO}\right)$, Cem. Concr. Res., 2001, 31, 13271332.

28 V. D. S. Ha, D. S. Kosson and Z. A. Van, Leaching, geochemical modelling and field verification of a municipal solid waste and a predominantly nondegradable waste landfill, Waste Manage., 2017, 63, 74.

29 A. Shahnazi, F. Rashchi and E. Vahidi, A Kinetics Study on the Hydrometallurgical Recovery of Vanadium from LD Converter Slag in Alkaline Media, John Wiley \& Sons, Inc., 2012.

30 G. E. Voglar and D. Leštan, Equilibrium leaching of toxic elements from cement stabilized soil, J. Hazard. Mater., 2013, 25, 246-247.

$31 \mathrm{~J}$. Tang and B. M. Steenari, Leaching optimization of municipal solid waste incineration ash for resource recovery: A case study of $\mathrm{Cu}, \mathrm{Zn}, \mathrm{Pb}$ and $\mathrm{Cd}$, Waste Manage., 2016, 48, 315-322.

32 I. H. Lee, Y. J. Wang and J. M. Chern, Extraction kinetics of heavy metal-containing sludge, J. Hazard. Mater., 2005, 123, 112.

33 Z. Makhloufi, E. H. Kadri, M. Bouhicha, A. Benaissa and R. Bennacer, The strength of limestone mortars with quaternary binders: Leaching effect by demineralized water, Constr. Build. Mater., 2012, 36, 171-181.

34 Q. F. Liu, G. L. Feng, J. Xia, J. Yang and L. Y. Li, Ionic transport features in concrete composites containing various shaped aggregates: a numerical study, Compos Struct., 2017, 183, 371-380.

35 J. Liu, F. Xing, B. Dong, H. Ma and D. Pan, Study on water sorptivity of the surface layer of concrete, Mater. Struct., 2014, 47, 1941-1951.

36 M. Frias, S. Goñi, R. García and R. V. D. L. Villa, Seawater effect on durability of ternary cements. Synergy of chloride and sulphate ions, Composites, Part B, 2013, 46, 173-178. 